This document is the accepted manuscript version of the following article:

Fernández-Ronco, M. P., Gradzik, B., Gooneie, A., Hufenus, R., \& El Fray, M. (2017). Tuning poly(3-hydroxybutyrate) (P3HB) properties by tailored segmented bio-copolymers. ACS Sustainable Chemistry and Engineering, 5(11), 11060-11068. http://doi .org/10.1021/acssuschemeng. 7 b03023

\title{
Tuning poly(3-hydroxybutyrate) (P3HB) properties by tailored segmented bio-copolymers
}

\author{
María P. Fernández-Ronco ${ }^{\mathrm{a}^{*}}$, Boguslawa Gradzik ${ }^{\mathrm{a}, \mathrm{b}}$, Ali Gooneie ${ }^{\mathrm{a}}$, Rudolf Hufenus ${ }^{\mathrm{a}}$, \\ Miroslawa El Fray ${ }^{b^{*}}$ \\ ${ }^{\mathrm{a}}$ Laboratory for Advanced Fibers, Empa - Swiss Federal Laboratories for Materials Science \\ and Technology. Lerchenfeldstrasse, 5. 9014 St. Gallen, Switzerland \\ ${ }^{\mathrm{b}}$ West Pomeranian University of Technology, Szczecin, Polymer Institute, Biomaterials and \\ Microbiological Technologies. Piastow, 45. 70-311 Szczecin, Poland \\ *Corresponding authors: \\ Tel.: +41 5876570 60. E-mail: maria.fernandez@empa.ch (M.P.Fernández-Ronco) \\ E-mail: Miroslawa.ElFray@zut.edu.pl (M. El Fray)
}

\begin{abstract}
Poly(3-hydroxybutyrate) (P3HB) is a thermoplastic, biocompatible and truly biodegradable polyester produced by bacteria, and characterized by a high degree of crystallinity due to its isotactic nature. In order to tackle the challenges of its processability at the time of developing new green materials, the use of biodegradable additives is highly recommended. In this work, the biodegradable and biocompatible semicrystalline multiblock copolyester poly(butylene succinate-butylene dilinoleate) (PBS:DLA), shortly abbreviated as CoPo, is used to produce new P3HB blends. The hard:soft segments ratio of the copolymer can be selected as desired during its synthesis. Two different copolymers, namely $\mathrm{CoPo}_{70}$ (70:30) and $\mathrm{CoPo}_{50}$ (50:50), were blended with $\mathrm{P} 3 \mathrm{HB}$ at different concentrations, i.e. 5, 10 and $20 \mathrm{wt} \%$, to investigate the phase behavior of blends. Furthermore, the effect of CoPo segmental composition and its content was evaluated experimentally as well as by dissipative particle dynamics (DPD) simulations. Results suggest the immiscibility of blends at bio-copolymer contents higher than $5 \mathrm{wt} \%$ for both copolymers with larger phase separated domains using $\mathrm{CoPo}_{70}$. It is found that the processability and the mechanical performance are dependent on the type and amount of bio-copolymer added to $\mathrm{P} 3 \mathrm{HB}$, allowing significant improvements with respect to the neat polymer. This work systematically compiles the processability and mechanical properties of different P3HB/PBS:DLA blends as a function of the hard:soft segments ratio of the CoPo. The selection of the most suitable blend will then depend on the processing requirements and specifications of the final green biomaterial and can be based on the results reported in this work.
\end{abstract}

Keywords: poly(3-hydroxybutyrate)(P3HB), multiblock copolyesters, dimer fatty acid, melt extrusion, polymer blends, dissipative particle dynamics 


\section{Introduction}

Poly(3-hydroxybutyrate) (P3HB) is a polymer produced as a storage medium by different bacteria ${ }^{1-3}$. As such it is bio-based (derived from renewable biological resources), biodegradable (degradable by biological means) and biocompatible (provoking no adverse effect on living systems) at the same time. The bacteria build the polymer chains perfectly linear and isotactic, which enables a high degree of crystallinity and exceptional properties ${ }^{4-6}$. Due to its properties and reasonable production costs, $\mathrm{P} 3 \mathrm{HB}$ is a promising substitute for conventional petrochemical plastics ${ }^{7-9}$. However, $\mathrm{P} 3 \mathrm{HB}$ has two major drawbacks that hinder its applicability for melt-processed products like fibers and films. On one hand, it undergoes rapid thermal degradation at temperatures just above the melting temperature, thus impeding melt-processing ${ }^{10-12}$. On the other hand, due to its intrinsic low nucleation density, it can form large spherulites, resulting in extreme brittleness ${ }^{13}$. In the latter case, nucleating agents and polymeric additives can accelerate crystallization and lead to smaller spherulites, thus improving ductility ${ }^{9,14-18}$.

To improve melt-processability, lubricants and plasticizers can be applied to decrease processing temperatures, thus reducing thermal degradation (loss of molecular weight) ${ }^{19}$. Lubricants facilitate movement of polymer chains without strongly influencing final properties of an extrudate (processing aids), while plasticizers promote movement of the chains to an extent that they decrease glass-transition temperature and increase ductility of a product ${ }^{20}$. To maintain biodegradability, non-toxic lubricants and plasticizers derived from naturally occurring resources are favored for this purpose ${ }^{21}$. Here, blending with another environmentally benign biopolymer is a very promising approach ${ }^{22}$ in the search of a "green" alternative to petrochemical plastics ${ }^{23,24}$, not only regarding an improvement in $\mathrm{P} 3 \mathrm{HB}$ processing, but also considering the blend as a new material for different applications, including biomedical approaches.

Therefore, many of the attempts reported in literature to blend P3HB with other biopolymers have been focused on applications in biomedical engineering ${ }^{25}$. Depending on their value of the free energy of mixing $\left(\Delta G_{\mathrm{m}}\right)$, polymer blends can be classified as completely miscible at a molecular level (homogeneous), partially miscible or immiscible (heterogeneous) at a larger length scale. The properties of a polymer blend ultimately depends on its final morphology ${ }^{26}$, which is itself a result of the energetic and entropic interactions of the polymer. These interactions are system dependent; hence the study of the phase behaviour should be conducted for each individual system. Nevertheless, the rule of "similar dissolves similar" could be employed as a rough approximation when selecting polymers to blend with the target, in this case P3HB. As such, common biopolyesters such as polycaprolactone (PCL) and poly(lactic acid) (PLA) have been extensively investigated, concluding that blends of P3HB with both polyesters of medium-high molecular weight are immiscible ${ }^{27-30}$, while the combination of $\mathrm{P} 3 \mathrm{HB}$ with copolymers of $\varepsilon$-caprolactone and $(R, S)$-lactide provides partially miscible blends as a function of composition ${ }^{31}$. A similar result was encountered by Qiu and coworkers when blending poly(butylene succinate) (PBS) with P3HB. The authors reported partial miscibility of $\mathrm{P} 3 \mathrm{HB} / \mathrm{PBS}$ solution casted blends at contents above $60 \%$ of $\mathrm{PBS}$, whereas at lower PBS contents all blends were immiscible ${ }^{32}$. For immiscible blends, the crystallization of the $\mathrm{P} 3 \mathrm{HB}$ fraction was enhanced by the incorporation of PBS, which might 
be interpreted as a result of the multi-nucleation mechanism that the PBS phase induces in the blend ${ }^{33}$. This phenomenon can promote a faster crystallization of $\mathrm{P} 3 \mathrm{HB}$, and hence introduces a potential improvement in the ductility.

Recently, a fully biodegradable and biocompatible multiblock thermoplastic elastomer (PBS:DLA) composed of soft segments of dilinoleic acid (DLA) and hard segments of poly(butylene succinate) has been synthesized ${ }^{34,35}$. Depending on the hard:soft segments ratio, the final properties of the bio-copolyesters $(\mathrm{CoPo})$ can be modified, ranging from stiff $(80: 20 \mathrm{wt} \%)$ to soft (40:60 wt\%) materials. Moreover, these bio-copolyesters show hydrolytic and enzymatic degradation, rendering them as interesting materials for medical applications, e.g. by preparing nanoparticles for drug delivery ${ }^{36}$, or as electrospun fibers ${ }^{37}$. By blending these bio-copolymers with $\mathrm{P} 3 \mathrm{HB}$, it is expected not only to affect the processability and mechanical properties of $\mathrm{P} 3 \mathrm{HB}$, but also to yield fully biodegradable and biocompatible blends to be used in different applications. In this work the preparation and characterization of P3HB/PBS:DLA blends was investigated for the first time. The phase behaviour of meltextruded blends was experimentally determined and compared to the predictions of dissipative particle dynamics (DPD) simulations as a function of blend concentration. Additionally, the preparation of P3HB/PBS:DLA blends containing bio-copolyesters of 70:30 $\left(\mathrm{CoPo}_{70}\right)$ and $50: 50\left(\mathrm{CoPo}_{50}\right)$ hard:soft segments ratio allowed us to elucidate how the interaction of polymer phases and the mechanical performance of final blends is affected by the hard:soft segments ratio of the bio-copolymer. All this information will serve as a roadmap for manufacturers using this biomaterial in a variety of specific applications.

\section{Experimental Section}

\section{Materials}

Poly(3-hydroxybutyrate) (P3HB) derived from bacteria, containing a maximum of $2 \%$ of biorest, was supplied in pellet form by Biomer (Krailling, Germany). Dimer fatty acid hydrogenated dilinoleic acid (DLA), trade name Pripol 1009, was provided by Croda (Gouda, Netherlands), and 1,4-butanediol (1,4-BD) and succinic acid (SA) by Sigma Aldrich (Poznan, Poland). Tetrabutyl titanate (TBT) was used as a catalyst (Sigma Aldrich, Poznan, Poland).

\section{Experimental methods}

\section{Synthesis of multiblock copolyester (CoPo)}

Multiblock poly(butylene succinate-butylene dilinoleate) (PBS:DLA) copolymers were prepared by melt polycondensation. The synthesis reaction was carried out in 1L stainless steel pressurized autoclave. The esterification reaction between hydrogenated dilinoleic acid (DLA), succinic acid (SA) and 1,4-butanediol (1,4-BD) was performed in the presence of tetrabutyl titanate (TBT) as a catalyst using intensive stirring and temperature ranging from $100{ }^{\circ} \mathrm{C}$ to $200{ }^{\circ} \mathrm{C}$ with a heating rate of $1.5^{\circ} \mathrm{C} / \mathrm{min}$. The reaction was finished when an acid value less than $2 \mathrm{mg} \mathrm{KOH} / \mathrm{g}$ was reached. Temperature of $250 \pm 5^{\circ} \mathrm{C}$ and $\sim 0.5 \mathrm{hPa}$ pressure during polycondensation reaction were kept constant. The process was considered complete 
when the observed power consumption of the stirrer motor signaled that the polymer of the highest melt viscosity was obtained. The reaction mass was collected by means of compressed nitrogen and purified by dissolution in chloroform and further precipitation in methanol. Two PBS:DLA copolymers with hard:soft segment composition $70: 30 \mathrm{wt} \%$ and 50:50 $\mathrm{wt} \%$, i.e. $\mathrm{CoPo}_{70}$ and $\mathrm{CoPo}_{50}$ respectively, were synthesized in this work. The chemical structure of segmented CoPo-s is shown in Figure 1, and for a complete NMR characterization of the biocopolymer the reader is referred to Jäger et al. ${ }^{36}$.

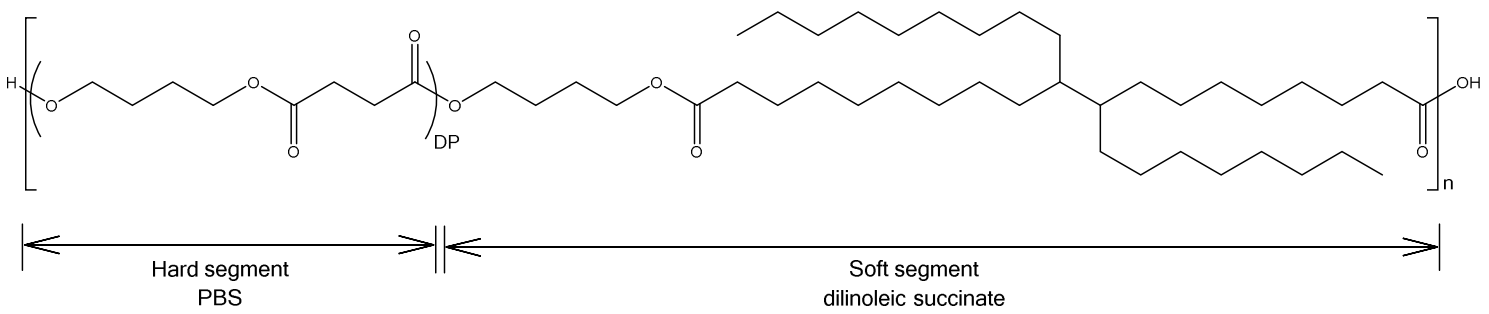

Figure 1. Chemical structure of PBS:DLA multiblock copolyester; DP refers to the degree of polycondensation of hard segments: $\mathrm{DP}=8.9(70: 30)$ and $\mathrm{DP}=3.8(50: 50)$

\section{Melt extrusion of P3HB/PBS:DLA (CoPo) blends}

$\mathrm{P} 3 \mathrm{HB} / \mathrm{CoPo}$ blends containing different amounts of copolymer $(5,10,20 \mathrm{wt} \%)$ of different segmental composition, namely 70:30 and 50:50, were prepared by melt extrusion in a corotating $36 \mathrm{~L} / \mathrm{D}$ twin screw extruder, (COLLIN GmbH, Germany). A $2 \mathrm{~mm}$ die and a throughput of $3 \mathrm{~g} / \mathrm{min}$ were selected for these experiments. The temperature profile of the seven heating zones of the extruder was selected as the lowest to achieve a proper processing of $\mathrm{P} 3 \mathrm{HB}$ without promoting its degradation, i.e. $145^{\circ} \mathrm{C}$ for the feed zone, $185{ }^{\circ} \mathrm{C}$ for zones 26 ; $180{ }^{\circ} \mathrm{C}$ for zone 7 and $172{ }^{\circ} \mathrm{C}$ for the die. A screw speed of $60 \mathrm{rpm}$ was used for all experiments. Prior to compounding, materials were dried at $60{ }^{\circ} \mathrm{C}$ for 24 hours, and corresponding proportions of $\mathrm{P} 3 \mathrm{HB}$ and $\mathrm{CoPos}$ were mixed for 1 hour at room temperature. Finally, the extruded polymer blends of $\mathrm{P} 3 \mathrm{HB} / \mathrm{CoPo}$ were quenched in a water bath and subsequently pelletized.

\section{Characterization}

\section{Gel permeation chromatography (GPC)}

Molecular weight of the blends was determined on a Viscotek triSEC model 302 GPC $\max /$ VE2001 system (Malvern, UK) at $35{ }^{\circ} \mathrm{C}$ by using chloroform as the eluent. Flow rate was set at $0.5 \mathrm{~mL} / \mathrm{min}$ and injection volume at $100 \mu \mathrm{L}$. The GPC system was equipped with modified styrene-divinylbenzene copolymer network columns and a refractive index detector. Polystyrene samples with a narrow molecular distribution (PS 10e7; 10e5; 10e3) were used as the standards to construct the GPC calibration curve. Molecular weights are then referred to PS standards. 
Thermal characterization of the blends was obtained by differential scanning calorimetry (DSC), using a Q100 device (TA Instruments, New Castle, DE, USA). For each measurement, $14 \mathrm{mg}$ of sample were pelletized and hermetically sealed in $50 \mu \mathrm{L}$ aluminum crucibles. Thermal history was deleted by heating up samples at $10{ }^{\circ} \mathrm{C} / \mathrm{min}$ from room temperature to $200^{\circ} \mathrm{C}$ and performing an isothermal step at $200^{\circ} \mathrm{C}$ for 2 minutes. Afterwards, samples were subjected to the following temperature program: 1) cooling ramp from $200{ }^{\circ} \mathrm{C}$ to $-100{ }^{\circ} \mathrm{C}$ at 5 ${ }^{\circ} \mathrm{C} / \mathrm{min}$; 2) heating ramp from $-100{ }^{\circ} \mathrm{C}$ to $200{ }^{\circ} \mathrm{C}$ at $10{ }^{\circ} \mathrm{C} / \mathrm{min}$. Three samples of each material were analyzed and the standard deviation calculated. Melting temperature $\left(\mathrm{T}_{\mathrm{m}}\right)$ was determined from the maximum peak value, while crystallization temperature $\left(T_{c}\right)$ was obtained from the onset of the thermal transition. Glass transition temperature $\left(\mathrm{T}_{\mathrm{g}}\right)$ corresponded to the midpoint of the thermal event. Nitrogen flow was $50 \mathrm{~mL} / \mathrm{min}$. The degree of crystallinity $\left(\mathrm{X}_{\mathrm{c}}\right)$ of neat $\mathrm{P} 3 \mathrm{HB}(1)$ and neat CoPo (2) blends was calculated using the following equations:

$$
\begin{gathered}
\mathrm{Xc}=\frac{\Delta \mathrm{H}_{\mathrm{m}}}{\Delta \mathrm{H}_{0}} \times 100 \\
\mathrm{Xc}=\frac{\Delta \mathrm{H}_{\mathrm{m}} \times \mathrm{SR}}{\Delta \mathrm{H}_{0}} \times 100
\end{gathered}
$$

where $\Delta \mathrm{H}_{0}$ is the melting enthalpy of $100 \%$ crystalline $\mathrm{P} 3 \mathrm{HB}(146.6 \mathrm{~J} / \mathrm{g})^{11}$, or of $100 \%$ crystalline PBS in the hard segments $(110.3 \mathrm{~J} / \mathrm{g})^{38}, \Delta \mathrm{H}_{\mathrm{m}}$ is the melting enthalpy of P3HB (1) or PBS:DLA copolymer (2), and SR refers to the hard:soft segment ratio in CoPo, namely 0.7 or 0.5 . Soft segments do not contribute to crystallinity.

Melt flow index (MFI)

Melt flow index values of P3HB and polymer blends were measured by a Melt Flow Indexer (Zwick Melt Flow Quick Index) at $190{ }^{\circ} \mathrm{C}$ and a load of $2.16 \mathrm{~kg}$, according to the ASTM standard D 1238-04. In each measurement, 5 grams of molten material flowed through an orifice of $2.0 \mathrm{~mm}$ diameter while the flowing time was recorded. Measurements were performed in triplicate and results are expressed in $\mathrm{g} / 10 \mathrm{~min}$.

\section{Scanning electron microscopy (SEM)}

Cryogenic fractures of $\mathrm{P} 3 \mathrm{HB}$ and polymer blends were observed with a Hitachi S-4800 scanning electron microscope. Before each analysis, samples were immersed in liquid $\mathrm{N}_{2}$ for 20 seconds and rapidly fractured, followed by sputtering with $3 \mathrm{~nm} \mathrm{Au} / \mathrm{Pd}$ using a Leica EM ACE 600 sputter coater. Photomicrographs of all samples were obtained using $2 \mathrm{mV}$ and 10 $\mu \mathrm{A}$.

\section{Optical microscopy}

Plates for optical microscopy observation were prepared using a Lindenberg Hot Press. $32 \mathrm{~g}$ of sample material were introduced in a $1 \mathrm{~mm}$ aluminium mould that was subjected to a 
maximum clamping force of 0.33 bar at $190{ }^{\circ} \mathrm{C}$ for 270 seconds. Polymer plates were then analysed by a digital microscope VHX-500F (Keyencé, Illinois, USA) to observe the macroscopic surface of the blends.

\section{Mechanical properties}

For mechanical tests, the extruded pellets of the polymer blends were injected molded into standard tensile bars (dumbbell-shaped / PN-EN ISO 527-2) using a BOY 32 injection molding machine without any previous thermal conditioning. The barrel temperature was set at $170{ }^{\circ} \mathrm{C}$ and the mold temperature at $115^{\circ} \mathrm{C}$. An injection pressure of 500 bar and a holding pressure of 70 bar were used. Mechanical tests were conducted at room temperature with a tensile testing machine (Instron 3366; Norwood, MA, USA) based on EN ISO 527-1:1998. Crosshead speed was set to $2 \mathrm{~mm} / \mathrm{min}$. 10 successful measurements were averaged and standard deviation (SD) was calculated.

\section{Dissipative Particle Dynamics (DPD) Simulations}

The morphologies of the $\mathrm{P} 3 \mathrm{HB} /$ bio-copolymer blends were investigated on a mesoscopic level utilizing the dissipative particle dynamics (DPD) simulation method ${ }^{39,40}$. In the simulations, a representative cubic cell of the blends with a side length of $75 \mathrm{~nm}$ containing various amounts of CoPo was simulated in a $14.2 \mu$ s timeframe. This setup allowed us to investigate the emerging morphological evolutions on a fine length scale. The details of the simulation methodology as well as the incorporated coefficients are discussed in full details in the Supporting Information.

\section{Results and Discussion}

Considering the special characteristics of the PBS-DLA copolymer, its incorporation into P3HB might not only allow a better processability of the polymer, but also a production of a fully biodegrable and biocompatible material ${ }^{36}$. Besides, considering the mechanical properties of the bio-copolymer which are affected by the hard:soft segments ratio ${ }^{34}$, it is expected that the addition of CoPo to $\mathrm{P} 3 \mathrm{HB}$ could potentially lead to a tunable control of the morphology and mechanics of the final blends, as it will be discussed as follows.

\section{Blends microstructure}

It is a common realization of polymer blends that the incorporation of a guest polymer as the dispersed phase in a host polymer as the matrix results in the formation of various morphologies with their majority being immiscible ${ }^{41}$. In order to investigate the morphology change in the blends after the addition of the bio-copolymers to the P3HB matrix, samples were studied utilizing optical microscopy and the results are shown in Figure 2. As it is observed in the micrographs, the blends are miscible up to a certain CoPo content, above which phase separation begins to dominate the morphology. A clear edge between the dispersed and the continuous phases is visible in the samples demonstrating a phase separation similar to other immiscible $\mathrm{P} 3 \mathrm{HB}$ blends such as $\mathrm{P} 3 \mathrm{HB} /$ poly(ethylene succinate), ${ }^{42}$ and $\mathrm{P} 3 \mathrm{HB} /$ poly( $\varepsilon$-caprolactone) ${ }^{30}$. This specific CoPo content appears to be critically 
dependent on the hard:soft segments ratio of the bio-copolymer and can be tuned to promote or diminish the phase separation. The most prominent difference between the developed morphologies is realized at $10 \mathrm{wt} \%$ of $\mathrm{CoPo}$ in $\mathrm{P} 3 \mathrm{HB}$. At this concentration $\mathrm{P} 3 \mathrm{HB} / \mathrm{CoPo}_{50}$ blend is miscible, while $\mathrm{P} 3 \mathrm{HB} / \mathrm{CoPo}_{70}$ blend undergoes microscopic phase separation. Considering the composition of each segment of the copolymer within the samples, the results indicate that the phase separation is dominant for $90 / 10_{70}, 80 / 20_{50}$ and $80 / 20_{70}$ blends. Therefore, a lower hard:soft segments ratio in the synthesized bio-copolymers, i.e. 50:50, favors a better miscibility up to higher bio-polymer contents. For the $\mathrm{P} 3 \mathrm{HB} / \mathrm{CoPo}_{50}$ blends the phase separation starts to control the morphology at a concentration between 10 to $20 \mathrm{wt} \%$, while this threshold concentration is between 5 to $10 \mathrm{wt} \%$ for the $\mathrm{P} 3 \mathrm{HB} / \mathrm{CoPo}_{70}$ blends. It should also be noted that the characteristic size of the separated phases in $80 / 20$ blends is smaller when $\mathrm{CoPo}_{50}$ is used as opposed to the larger segregated domains of $\mathrm{CoPo}_{70}$. This might be associated to the higher content of the soft segments in $\mathrm{CoPo}_{50}$ that limits the crystal growth of the hard-segment domains, in that way softening the transition between both phases and allowing a proper morphology control by selecting the composition of the biocopolyester.

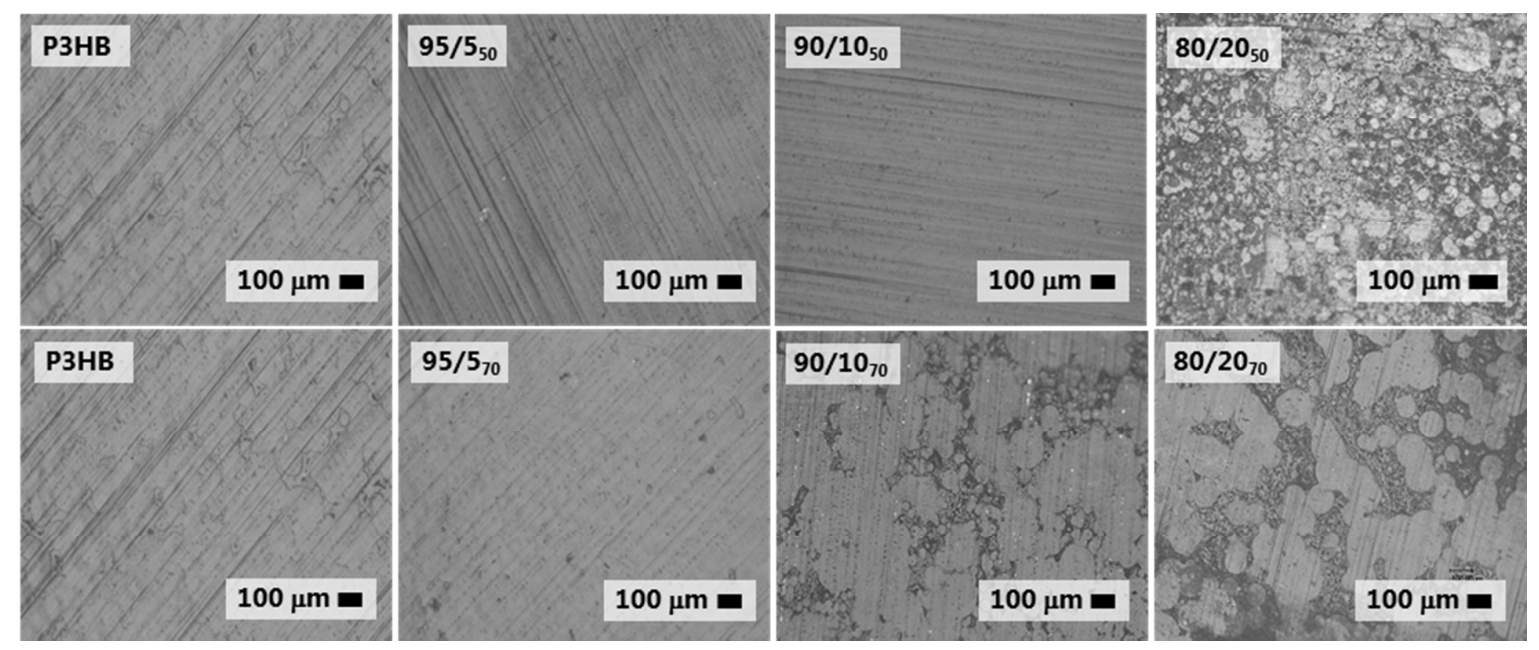

Figure 2. Optical micrographs of P3HB/PBS:DLA blends prepared with different weight contents of CoPo of different segmental composition. Subscripts indicate the type of CoPo employed in the blends (upper row $-\mathrm{CoPo}_{50}$, lower row $-\mathrm{CoPo}_{70}$ ). Neat $\mathrm{P} 3 \mathrm{HB}$ is shown at the left-hand side for comparison purposes.

To investigate the morphology on a finer length scale than the one detectable via optical microscopy, DPD simulations were employed to theoretically predict the phase behavior of blends. The corresponding results are shown in Figure 3. 

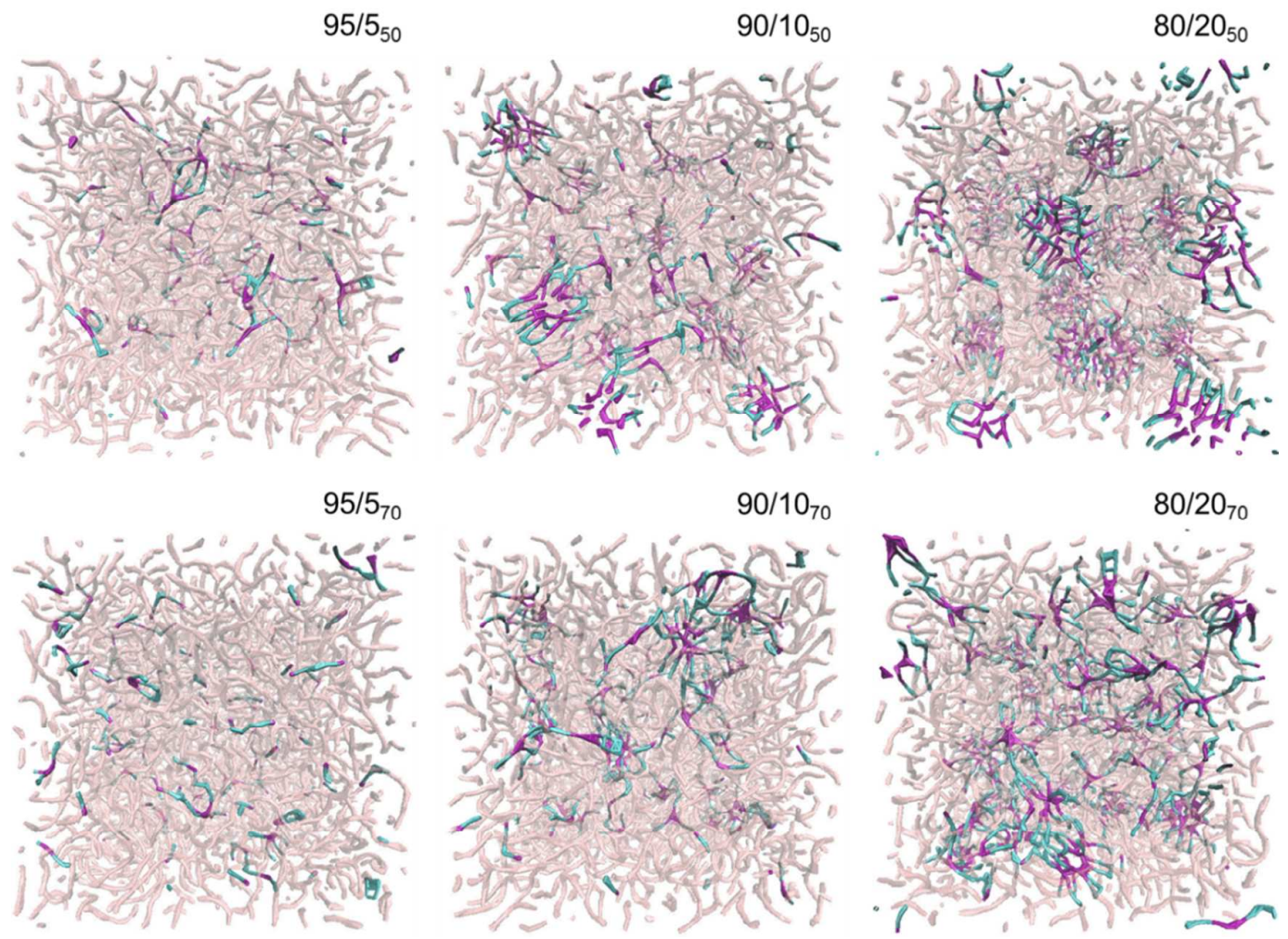

Figure 3. Snapshots obtained from DPD simulations conducted to evaluate the phase behaviour of P3HB/PBS:DLA blends at $190{ }^{\circ} \mathrm{C}$ (box length: $75 \mathrm{~nm}$ ). Colors refer to: P3HB (pale pink), CoPo hard segments (purple), CoPo soft segments (turquoise).

The overall morphology patterns of blends are similar to the optical microscopy results, suggesting a promoted phase separation for higher CoPo contents and hard:soft segments of the bio-copolymer. Considering the DPD results of blends containing $20 \mathrm{wt} \%$ of $\mathrm{CoPo}$, the morphology of the phase separation displayed by the simulations is rather comparable to the experimental results. Actually, at lower hard:soft segments ratios in the $\mathrm{CoPo}$, i.e. $\mathrm{CoPo}_{50}$, it is suggested that the soft segments of the bio-copolymer stabilize the formation of spherical clusters within the continuous P3HB phase. These clusters contain the PBS hard segments oriented internally, whereas the DLA soft segments act as an external barrier resembling the structure of micelles, and providing the characteristic well-defined spherical shape that is also observable in Figure 2. When the hard:soft segments ratio of the bio-copolymer increases, the structure disentangles, rendering bigger phase separated domains of CoPo with an undefined shape. We should remark that whereas simulations at $5 \mathrm{wt} \%$ and $20 \mathrm{wt} \%$ of both CoPo's perfectly match the experimental observations, at $10 \mathrm{wt} \% \mathrm{CoPo}_{50}$ a mismatch exists. Actually, simulations predict phase separation which is not visible in the microscopy images. An explanation for this should be encountered in two factors: 1) the extension of the phase separation, and 2) the different length scale of both images. If phase separation starts at this concentration and is not sufficient to homogeneously distribute through the sample, the difference in length scale of both figures (Figure 2, hundreds of microns; Figure 3, just 75 $\mathrm{nm}$ ) will impede their actual comparison. Mild phase separation at $10 \mathrm{wt} \% \mathrm{CoPo}_{50}$ might actually be present but not observable by optical microscopy. 
Provided that the observed morphologies in the microscopy images do not merely dominate locally, they should also manifest themselves in the collective thermal transitions of the blends. Therefore, DSC measurements were carried out to determine whether the observations encountered by image analysis can be corroborated by the thermal transitions observed in the blends. While Table 1 compiles the values of all thermal transitions, Figure 4 reports the thermograms of the different P3HB/PBS:DLA blends. Utilizing the melting enthalpy of the neat components $\left(\Delta \mathrm{H}_{\mathrm{m}}\right)$, the degree of crystallinity was calculated. The results show clearly that $\mathrm{P} 3 \mathrm{HB}$ is highly crystalline $(\mathrm{Xc}=65 \%)$, contrary to both copolymers whose lower degrees of crystallinity critically depend on their hard:soft segments ratio $(\mathrm{Xc}=31 \%$ and $\mathrm{Xc}=15 \%$ for $\mathrm{CoPo}_{70}$ and $\mathrm{CoPo}_{50}$, respectively). The incorporation of the bio-copolymer to $\mathrm{P} 3 \mathrm{HB}$ reduces therefore the overall crystallinity of the blend (data not shown), what might be beneficial to increase the brittle-ductile transition temperature and to ease ductility of the final product ${ }^{43}$. Considering the number of thermal transitions, the second heating cycle of $\mathrm{P} 3 \mathrm{HB} / \mathrm{CoPo}$ blends (Figure 4a) shows two melting transitions for all CoPo contents representing the melting of each phase. In the cooling cycle (Figure 4b), two thermal transitions are as well visible for all blends. The first exothermic peak at the highest temperature is related to the crystallization of the miscible components in the continuous phase, which is mainly composed of $\mathrm{P} 3 \mathrm{HB}$, while the second thermal event is associated with the glass transition temperature of $\mathrm{P} 3 \mathrm{HB}$, i.e. $5.7 \pm 0.3^{\circ} \mathrm{C}$. By increasing the content of the bio-copolymer above $5 \mathrm{wt} \%$ in the blends, an additional distinct exothermic peak $\left(\mathrm{T}_{\mathrm{c} 2}\right)$ can be distinguished in the thermograms. This thermal transition results from the crystallization of the CoPo dispersed phase domains which are present in the blends, and it confirms the phase separation predicted by the DPD simulations for $90 / 10_{50}$ blends (Figure 3 ), in contrast to the observations of the microscopy images that displayed a fully miscible blend at bigger length scales.

(a)

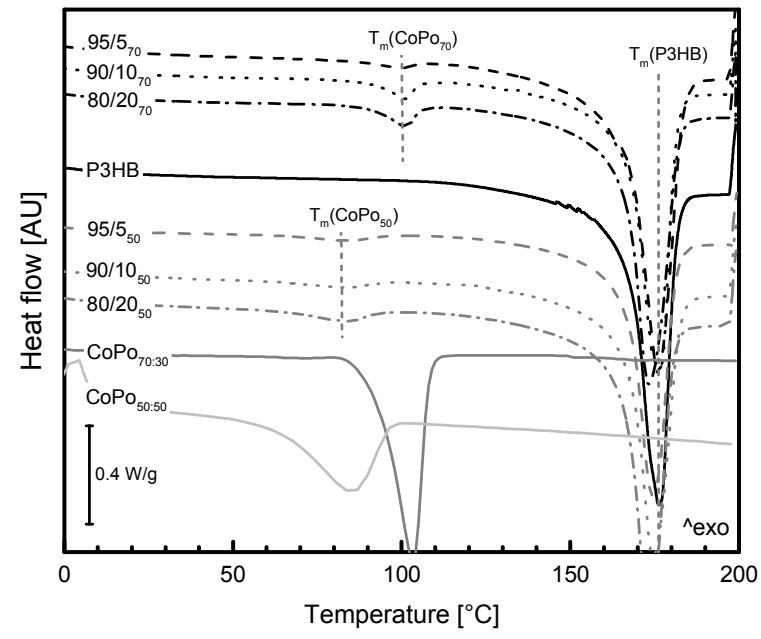

(b)

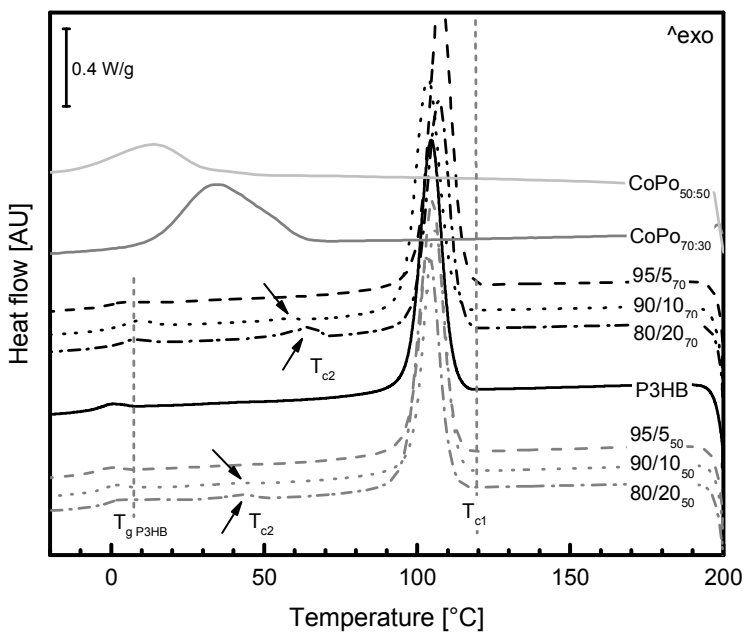

Figure 4. Heating (a) and cooling (b) thermograms of the different P3HB/CoPo blends. In figure (b) arrows represent extra thermal events which are associated with the phase separation observed in those blends. 
Table 1. Values of the thermal transitions of the neat components and of the polymer blends analysed by DSC. Subscripts refer to the position of the thermal event in the thermogram from right to left.

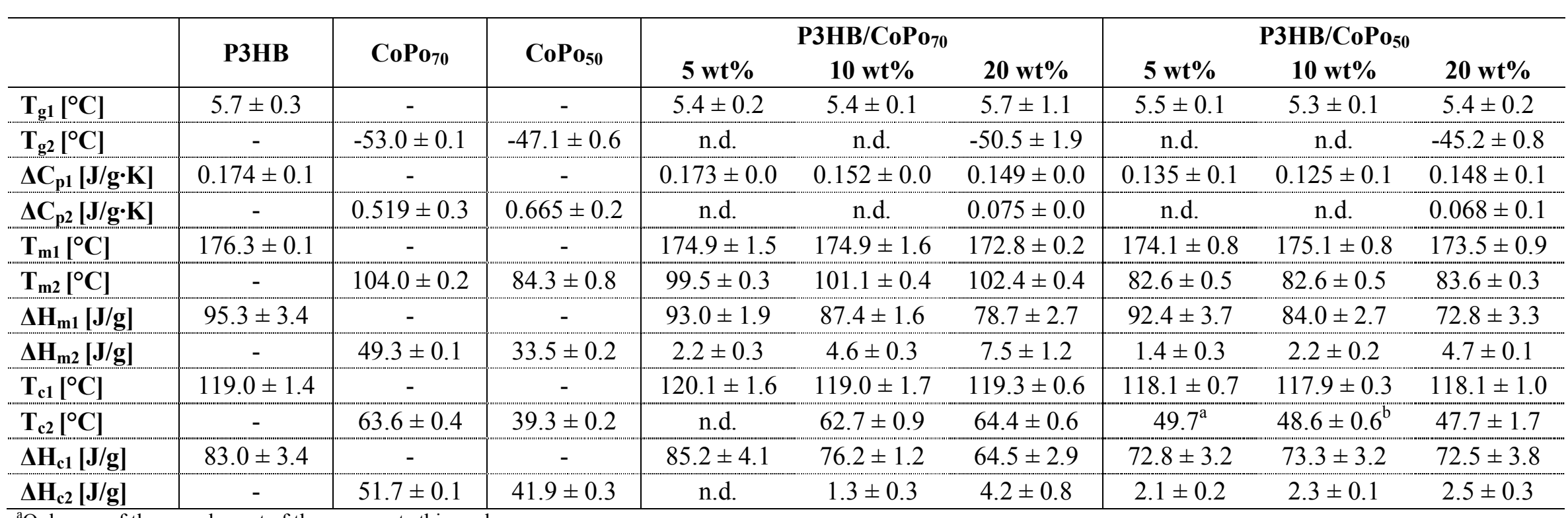

${ }^{\mathrm{a}}$ Only one of the samples out of three presents this peak.

${ }^{\mathrm{b}}$ Only two of the samples out of three present this peak.

n.d. Not detected 
The incorporation of the synthesized bio-copolymers in the P3HB matrix not only affects the microscopic morphology, but also imparts certain effects to the material behavior on a molecular level. A noticeable difference stems from the realization that, in general, the shorter chains of the copolymer molecules depict faster dynamics in comparison to the longer $\mathrm{P} 3 \mathrm{HB}$ macromolecules ${ }^{44}$. In order to investigate the overall molecular weights of the samples, GPC measurements were conducted. The $\mathrm{M}_{\mathrm{n}}$ and $\mathrm{M}_{\mathrm{w}}$ values of the neat components and their blends with different amount of CoPo are summarized in Table 2. In general, P3HB has a higher molar mass $\left(\mathrm{M}_{\mathrm{n}}=137 \mathrm{kDa}, \mathrm{M}_{\mathrm{w}}=404 \mathrm{kDa}\right)$ as compared to $\mathrm{CoPo}_{70}\left(\mathrm{M}_{\mathrm{n}}=45 \mathrm{kDa}\right.$, $\left.\mathrm{M}_{\mathrm{w}}=106 \mathrm{kDa}\right)$ and $\mathrm{CoPo}_{50}\left(\mathrm{M}_{\mathrm{n}}=48 \mathrm{kDa}, \mathrm{M}_{\mathrm{w}}=131 \mathrm{kDa}\right)$. The molecular characteristics of $\mathrm{P} 3 \mathrm{HB}$ are in good agreement with literature data ${ }^{11,45}$. As expected, the number and weight average molecular weights of the polymer blends decrease with increasing amount of CoPo. The reduction of the overall molecular weights of the blends by adding CoPo will in turn affect the processability and mechanical properties of the blends as will be discussed in the next section.

Table 2. The $\mathrm{M}_{\mathrm{n}}, \mathrm{M}_{\mathrm{w}}$ and polydispersity index $\left(\mathrm{M}_{\mathrm{w}} / \mathrm{M}_{\mathrm{n}}\right)$ of blends containing different amounts of CoPo of different hard:soft segments ratio.

\begin{tabular}{c|ccc|ccc} 
& \multicolumn{3}{|c|}{$\mathbf{C o P o}_{\mathbf{7 0}}$} & \multicolumn{3}{c}{$\mathbf{C o P o}_{50}$} \\
\hline $\begin{array}{c}\text { P3HB/CoPo } \\
{[\mathbf{w t} \%]}\end{array}$ & $\begin{array}{c}\mathbf{M}_{\mathbf{n}} \\
{[\mathbf{k D a}]}\end{array}$ & $\begin{array}{c}\mathbf{M}_{\mathbf{w}} \\
{[\mathbf{k D a}]}\end{array}$ & $\begin{array}{c}\mathbf{M}_{\mathbf{w}} / \mathbf{M}_{\mathbf{n}} \\
{[-]}\end{array}$ & $\begin{array}{c}\mathbf{M}_{\mathbf{n}} \\
{[\mathbf{k D a}]}\end{array}$ & $\begin{array}{c}\mathbf{M}_{\mathbf{w}} \\
{[\mathbf{k D a}]}\end{array}$ & $\begin{array}{c}\mathbf{M}_{\mathbf{w}} / \mathbf{M}_{\mathbf{n}} \\
{[-]}\end{array}$ \\
\hline $100 / 0$ & 137 & 404 & 2.9 & 137 & 404 & 2.9 \\
$95 / 5$ & 180 & 386 & 2.1 & 118 & 317 & 2.6 \\
$90 / 10$ & 108 & 300 & 2.7 & 108 & 332 & 3.0 \\
$80 / 20$ & 77 & 217 & 2.8 & 94 & 269 & 2.8 \\
$0 / 100$ & 45 & 106 & 2.3 & 48 & 131 & 2.7 \\
\hline
\end{tabular}

\section{Tunable processability and mechanics of $\mathrm{P3HB} / \mathrm{CoPo}$ blends}

Due to its relatively low decomposition temperature, P3HB can easily degrade during meltprocessing, which facilitates its processability at the expense of a poorer mechanical performance. An alternative approach towards the improved processability is the addition of lubricants or plasticizers to the polymer matrix, which reduces the overall viscosity. Considering the effects the synthesized bio-copolymers have on the molecular weight of the blends, one can expect a lubricating or plasticizing effect in $\mathrm{P} 3 \mathrm{HB} / \mathrm{CoPo}$ samples. Following ${ }^{24,46}$, we evaluated the average MFI values of the blends as a direct indication of their processability, and report the results in Table 3. It can be concluded that CoPo molecules act as lubricants and increase the MFI values, particularly at high loadings.

Table 3. MFI values of polymer blends containing different amounts of CoPo of different hard:soft segments ratio.

\begin{tabular}{ccc}
\hline \multirow{2}{*}{ P3HB/CoPo [wt\%] } & \multicolumn{2}{c}{ MFI [g/10 min] } \\
& CoPo $_{\mathbf{7 0}}$ & CoPo $_{50}$ \\
\hline $100 / 0$ & $5.0 \pm 0.3$ & $5.0 \pm 0.3$ \\
$95 / 5$ & $5.0 \pm 0.1$ & $5.1 \pm 0.07$ \\
$90 / 10$ & $5.6 \pm 0.03$ & $5.1 \pm 0.07$ \\
$80 / 20$ & $10.7 \pm 0.3$ & $7.1 \pm 0.1$ \\
\hline
\end{tabular}


The processability of the blends defined in terms of the MFI parameter depends on the hard:soft segments ratio of the bio-copolymers as is depicted in Figure 5, particularly for blends containing $20 \mathrm{wt} \%$ of CoPo. At the low CoPo content of $5 \mathrm{wt} \%$, MFI values are analogous to pure $\mathrm{P} 3 \mathrm{HB}$, indicating that the addition of CoPo does not promote any further degradation of $\mathrm{P} 3 \mathrm{HB}$ under the processing conditions employed in this work. The results show that the formation of dispersed phase on larger length scales enhances the meltprocessing of $\mathrm{P} 3 \mathrm{HB}$ to a greater extent, as opposed to the miscible blends. This effect might be attributed to the easier relocation of the low molecular weight copolymers to the stress concentration zones in the processing device, thus lubricating the material flow.

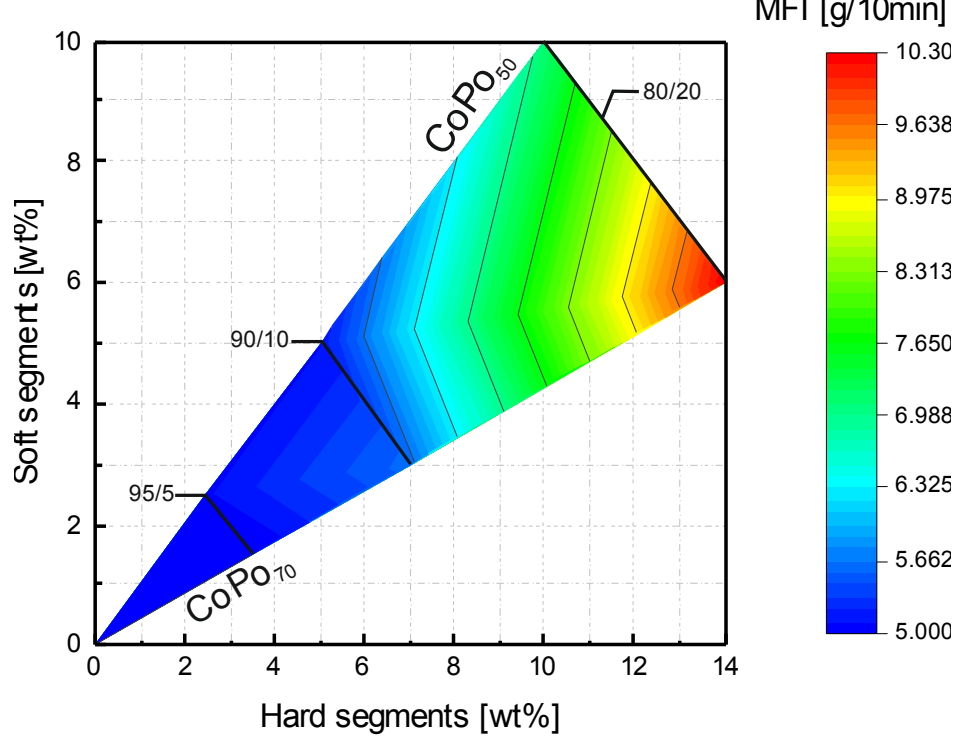

Figure 5. Processability expressed in terms of MFI values as a function of the hard and soft segments present in different $\mathrm{P} 3 \mathrm{HB} / \mathrm{CoPo}$ blends.

Considering the different processability of blends as a function of amount and hard:soft segments ratio of the bio-copolymer, mechanical properties of final products are likely to be different from those of $\mathrm{P} 3 \mathrm{HB}$, except for the brittleness, which is not expected to change drastically. Actually, due to the poor interfacial adhesion observed between $\mathrm{P} 3 \mathrm{HB}$ and CoPo in microscopic images, the stress applied to the sample is not effectively transferred to the dispersed phase ${ }^{47}$. As a result, $\mathrm{P} 3 \mathrm{HB}$ should bear almost all the stress, which leads to brittle fracture of the blends, as confirmed by the SEM micrographs of the cryo-fracture surface of neat $\mathrm{P} 3 \mathrm{HB}$ and $\mathrm{P} 3 \mathrm{HB} / \mathrm{CoPo}$ blends (Figure S1).

In Figure 6, the Young's modulus, tensile strength, elongation at break and toughness of all blends are presented as a function of the block ratio of the bio-copolymers. The addition of the bio-copolymer softens the polymeric matrix, especially at low hard:soft segments ratios (Figure 6a). This can be ascribed to the flexibility of the bio-copolymer, which increases with the amount of soft segments ${ }^{34}$. The reduction of the Young's modulus is at the upper limit at the highest global soft segments content, i.e. $\mathrm{CoPo}_{50}$ at $20 \mathrm{wt} \%$. Tensile strength and toughness (Figure $6 \mathrm{~b}$ and $\mathrm{d}$ ) could benefit from the presence of higher hard:soft segments ratios provided that a good interfacial adhesion is assured between matrix and dispersed phase, suffering a drop in their values when the soft segments dominate the behavior of the 
bio-copolymer. This latter finding might be associated to the lubrication effect of the soft segments that results at the same time in a higher elongation at break (Figure 6c). Overall, it is evident that the mechanical performance of the final products is intimately related to the addition of the bio-copolymer and can be tuned by controlling the hard:soft segments ratio of the CoPo incorporated in P3HB.
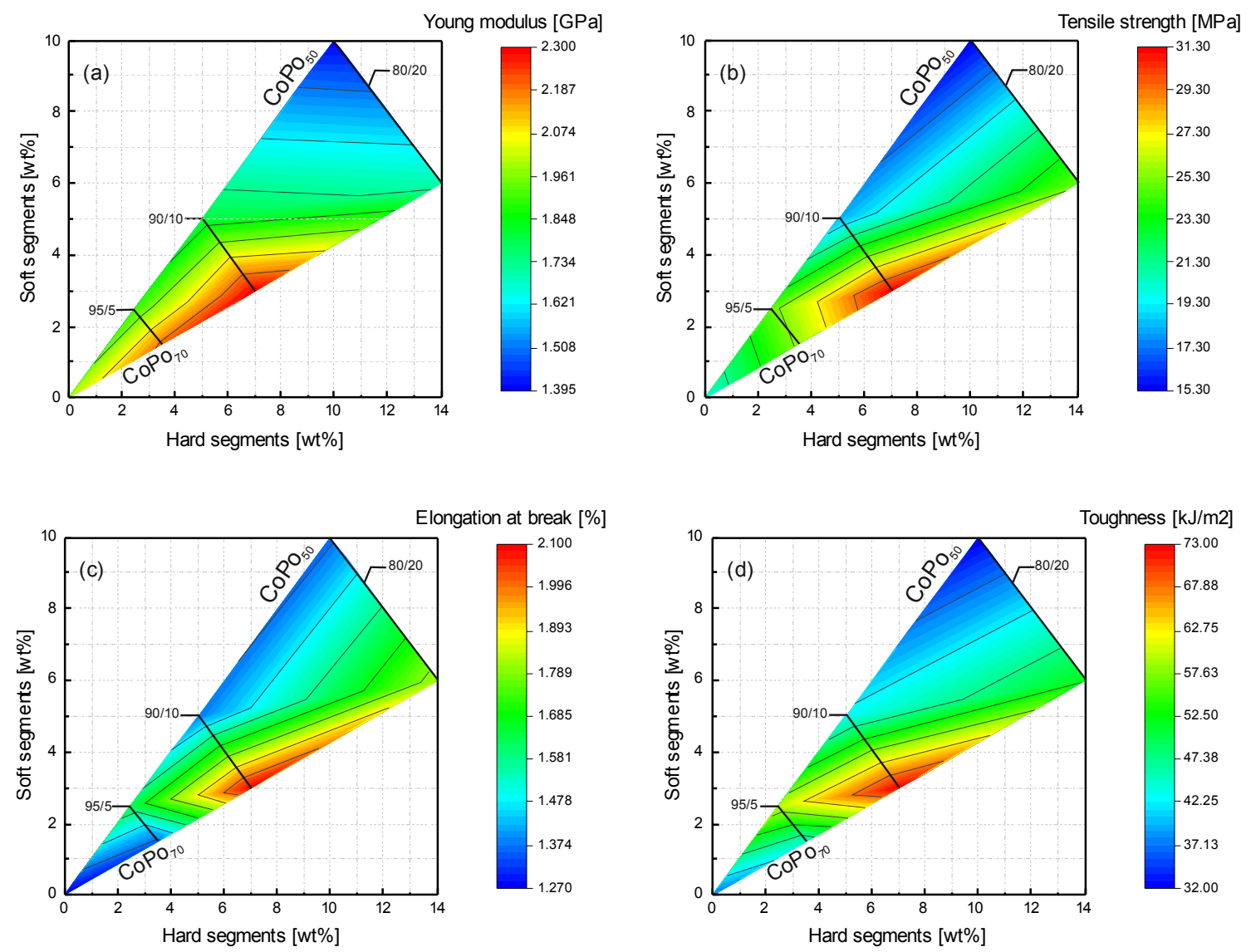

Figure 6. (a) Young's modulus, (b) tensile strength, (c) elongation at break, and (d) toughness as a function of the hard and soft segments present in different $\mathrm{P} 3 \mathrm{HB} / \mathrm{CoPo}$ blends.

Taking the MFI data into account, it appears that the processability and mechanical performance of the blends are strongly influenced by the composition of the blends, as well as by the hard:soft segments ratio of the bio-copolymers. The $80 / 20 \mathrm{P} 3 \mathrm{HB} / \mathrm{CoPo}_{70}$ blend shows the highest MFI value among all samples. For this blend, the Young's modulus is slightly lower than that of the pure P3HB (1.7 GPa as opposed to $2.0 \mathrm{GPa}$, Table S2 in SI), whereas the tensile strength, the elongation at break, and the toughness have larger values than those of the pure $\mathrm{P} 3 \mathrm{HB}$. On the other hand, the $90 / 10 \mathrm{P} 3 \mathrm{HB} / \mathrm{CoPo}_{70}$ blend exhibits the best mechanical performance while its MFI value is only slightly larger than that of the pure $\mathrm{P} 3 \mathrm{HB}$ matrix. These trends in the data provide us with the opportunity to design a specific blend to fulfill a certain property profile requirement, benefitting from a proper phase composition and bio-copolymer segmental ratio.

Before closing the discussion, the role of interfacial adhesion in the developed mechanical performance of the blends should be mentioned. From the profiles of the mechanical 
properties as function of the hard:soft segments ratio of the bio-copolymers, it is clear that the 90/10 $\mathrm{P} 3 \mathrm{HB} / \mathrm{CoPo}_{70}$ blend is the sample showing optimum mechanical properties. Considering the dominant phase separated morphology of this sample, one should inspect the role of the interface on the mechanics of the blends. As noted before, since the overall behavior of the blend is brittle, which suggests a poor interfacial adhesion between the phases, it is rather unexpected that the blend shows such improved mechanical performance compared to pure P3HB. For this reason, a further study on this issue would be necessary to reveal critical information about the interface of these blends.

\section{Conclusions}

In the search of improving the processability of $\mathrm{P} 3 \mathrm{HB}$, a new fully biodegradable material has been described in this work. A polymer blend based on poly(3-hydroxybutyrate) (P3HB) and multiblock copolyester, PBS:DLA (CoPo), was developed by melt-extrusion and its phase behavior was investigated. The incorporation of the bio-copolymer into $\mathrm{P} 3 \mathrm{HB}$ renders blends that are partially miscible at low CoPo concentrations and become immiscible at contents higher than $5 \mathrm{wt} \%$, independent of the hard:soft segments ratio of the bio-copolymer. From DPD simulations, the morphology of phase separated domains of $\mathrm{CoPo}_{50}$ resembles those of micelles. PBS hard segments are oriented internally, while DLA soft segments act as an external barrier that limits the crystal growth of the hard segments and leads to the formation of small well-defined spherical CoPo domains within the P3HB continuous phase. By increasing the hard:soft segments ratio of the copolymer $\left(\mathrm{CoPo}_{70}\right)$, the stabilization with micelle morphology is no longer possible and bigger domains of the bio-copolymer with a non-defined shape appear in the continuous phase. It seems that the realization of these domains, as well as a drop in the molecular weight of the blends improve the processability of P3HB as indicated by higher melt flow indexes. In that case, PBS:DLA act as a lubricant of $\mathrm{P} 3 \mathrm{HB}$ and could potentially lead to the reduction of processing temperatures and thus hinder degradation of the polymer.

Considering the mechanical performance of the new biodegradable biomaterial, P3HB/PBS:DLA, the content and segmental composition of the bio-copolymer added to $\mathrm{P} 3 \mathrm{HB}$ allow tuning the mechanics of the final product. Blends containing $10 \mathrm{wt} \% \mathrm{CoPo}_{70}$ showed the best mechanical performance in terms of tensile strength, toughness and elongation at break. However, the processability, expressed in terms of MFI values, was only slightly improved with respect to neat P3HB. The highest MFI value was obtained for blends of $20 \mathrm{wt} \% \mathrm{CoPo}_{70}$ at the expense of a reduction in mechanical performance, which was slightly better than that of neat P3HB. Therefore, the selection of type and amount of CoPo to be blended with $\mathrm{P} 3 \mathrm{HB}$ relies on the processing necessities and the specific requirements of the final product, and must be balanced in terms of processability and mechanical performance. We believe that the results reported in this work throw light on this direction, allowing future researches to address the correct selection of the bio-copolymer to be added to P3HB. 


\section{Supporting Information}

1. Simulation details: polymer model; DPD units and model parameters; simulation methods. 2. Mechanical properties: averaged value of the main mechanical properties of $\mathrm{P} 3 \mathrm{HB} / \mathrm{CoPo}$ blends. 3. SEM images of the cryo-fracture of P3HB and P3HB/CoPo blends.

\section{Acknowledgements}

The authors thank Zdzislaw Mackow for CoPo synthesis, Benno Wüst and Mathias Lienhard for extrusion trials and melt flow index measurements, and the Swiss Confederation through the Swiss Sciex-NMS ${ }^{\text {ch }}$ programme (grant 13.198) for funding.

\section{References}

(1) Leja, K.; Lewandowicz, G. Polymer biodegradation and biodegradable polymers - A review. Polish J. Environ. Stud. 2010, 19 (2), 255-266.

(2) Sudesh, K.; Abe, H.; Doi, Y. Synthesis, structure and properties of polyhydroxyalkanoates: biological polyesters. Prog. Polym. Sci. 2000, 25 (10), 15031555. DOI: 10.1016/S0079-6700(00)00035-6.

(3) Poli, A.; Di Donato, P.; Abbamondi, G. R.; Nicolaus, B. Synthesis, Production, and Biotechnological Applications of Exopolysaccharides and Polyhydroxyalkanoates by Archaea. Archaea 2011, 2011, 1-13. DOI: 10.1155/2011/693253.

(4) Pan, P.; Inoue, Y. Polymorphism and isomorphism in biodegradable polyesters. Prog. Polym. Sci. 2009, 34 (7), 605-640. DOI: 10.1016/j.progpolymsci.2009.01.003.

(5) Yokouchi, M.; Chatani, Y.; Tadokoro, H.; Teranishi, K.; Tani, H. Structural studies of polyesters: 5. Molecular and crystal structures of optically active and racemic poly ( $\beta$ hydroxybutyrate). Polymer (Guildf). 1973, 14 (6), 267-272. DOI: 10.1016/00323861(73)90087-6.

(6) Lenz, R. W.; Marchessault, R. H. Bacterial Polyesters: Biosynthesis, Biodegradable Plastics and Biotechnology. Biomacromolecules 2005, 6 (1), 1-8. DOI: 10.1021/bm049700c.

(7) Choi, J. I.; Lee, S. Y. Process analysis and economic evaluation for poly(3hydroxybutyrate) production by fermentation. Bioprocess Eng. 1997, 17 (6), 335-342. DOI: $10.1007 / \mathrm{s} 004490050394$.

(8) Leong, Y. K.; Show, P. L.; Ooi, C. W.; Ling, T. C.; Lan, J. C.-W. Current trends in polyhydroxyalkanoates (PHAs) biosynthesis: Insights from the recombinant Escherichia coli. J. Biotechnol. 2014, 180 (0), 52-65. DOI: 10.1016/j.jbiotec.2014.03.020.

(9) Laycock, B.; Halley, P.; Pratt, S.; Werker, A.; Lant, P. The chemomechanical properties of microbial polyhydroxyalkanoates. Prog. Polym. Sci. 2014, 39 (2), 397 442. DOI: 10.1016/j.progpolymsci.2012.06.003. 
(10) Vogel, R.; Tändler, B.; Voigt, D.; Jehnichen, D.; Häussler, L.; Peitzsch, L.; Brünig, H. Melt spinning of bacterial aliphatic polyester using reactive extrusion for improvement of crystallization. Macromol. Biosci. 2007, 7 (6), 820-828. DOI: 10.1002/mabi.200700041.

(11) Barham, P. J.; Keller, A.; Otun, E. L.; Holmes, P. A. Crystallization and morphology of a bacterial thermoplastic: poly-3-hydroxybutyrate. J. Mater. Sci. 1984, 19 (9), 27812794. DOI: $10.1007 / \mathrm{s} 10973-011-1768-2$.

(12) Chodak, I.; Blackburn, R. S. Poly(hydroxyalkanoates) and poly(caprolactone). In Biodegradable and sustainable fibres; Blackburn, R. S., Ed.; Woodhead Publishing Limited: Cambridge, 2005; pp 221-244. DOI: 10.1533/9781845690991.221.

(13) Holmes, P. A. Biologically produced (R)-3-hydroxyalkanoate polymers and copolymers. In Developments in crystalline polymers; Elsevier Applied Science Publishers Ltd: Essex, UK, 1988; pp 1-65. DOI: 10.1007/978-94-009-1341-7_1.

(14) Wang, L. A.; Zhu, W. F.; Wang, X. J.; Chen, X. A.; Chen, G. Q.; Xu, K. T. Processability modifications of poly(3-hydroxybutyrate) by plasticizing, blending, and stabilizing. J. Appl. Polym. Sci. 2008, 107 (1), 166-173. DOI: 10.1002/app.27004.

(15) Baltieri, R. C.; Mei, L. H. I.; Bartoli, J. Study of the influence of plasticizers on the thermal and mechanical properties of poly(3-hydroxybutyrate) compounds. Macromol. Symp. 2003, 197, 33-44. DOI: 10.1002/masy.200350704.

(16) An, Y.; Dong, L.; Li, G.; Mo, Z.; Feng, Z. Miscibility, crystallization kinetics, and morphology of poly( $\beta$-hydroxybutyrate) and poly(methyl acrylate) blends. J. Polym. Sci. Part B Polym. Phys. 2000, 38 (14), 1860-1867. DOI: 10.1002/10990488(20000715)38:14<1860::AID-POLB40>3.0.CO;2-\#.

(17) Kai, W.; He, Y.; Inoue, Y. Fast crystallization of poly(3-hydroxybutyrate) and poly(3hydroxybutyrate-co-3-hydroxyvalerate) with talc and boron nitride as nucleating agents. Polym. Int. 2005, 54 (5), 780-789. DOI: 10.1002/pi.1758.

(18) El-Hadi, A.; Schnabel, R.; Straube, E.; Müller, G.; Henning, S. Correlation between degree of crystallinity, morphology, glass temperature, mechanical properties and biodegradation of poly (3-hydroxyalkanoate) PHAs and their blends. Polym. Test. 2002, 21 (6), 665-674. DOI: 10.1016/S0142-9418(01)00142-8.

(19) Hufenus, R.; Reifler, F. A.; Fernández-Ronco, M. P.; Heuberger, M. Molecular orientation in melt-spun poly(3-hydroxybutyrate) fibers: effect of additives, drawing and stress-annealing. Eur. Polym. J. 2015, 71, 12-26. DOI: 10.1016/j.eurpolymj.2015.07.039.

(20) Lutz Jr, J. T.; Grossman, R. F. Polymer Modifiers and Additives; Marcel Dekker Inc: New York, 1988.

(21) Erceg, M.; Kovačić, T.; Klarić, I. Thermal degradation of poly(3-hydroxybutyrate) plasticized with acetyl tributyl citrate. Polym. Degrad. Stab. 2005, 90 (2), 313-318. DOI: $10.1016 /$ j.polymdegradstab.2005.04.048.

(22) Avella, M.; Martuscelli, E.; Raimo, M. Properties of blends and composites based on poly(3-hydroxy)butyrate (PHB) and poly(3-hydroxybutyrate-hydroxyvalerate) (PHBV) copolymers. J. Mater. Sci. 2000, 35 (3), 523-545. DOI: 10.1023/A:1004740522751. 
(23) Dhaman, Y.; Ugwu, C. U. Poly [(R)-3-hydroxybutyrate]: the Green Biodegradable Bioplastics of the Future. Ferment Technol 2013, 3, 1000111. DOI: 10.4172/21677972.1000e120.

(24) Zhang, K.; Misra, M.; Mohanty, A. K. Toughened Sustainable Green Composites from Poly(3-hydroxybutyrate- co -3-hydroxyvalerate) Based Ternary Blends and Miscanthus Biofiber. ACS Sustain. Chem. Eng. 2014, 2 (10), 2345-2354. DOI: 10.1021/sc500353v.

(25) Zhu, C.; Chen, Q. Polyhydroxyalkanoate-Based Biomaterials for Applications in Biomedical Engineering. Adv. Healthc. Mater. 2014, 439-464. DOI: $10.1002 / 9781118774205 . \operatorname{ch} 12$.

(26) Thomas, S.; Grohens, Y.; Jyotishkumar, P. Polymer Blends: State of the Art, New Challenges, and Opportunities. In Characterization of Polymer Blends: Miscibility, Morphology and Interfaces; Thomas, S., Grohens, Y., Jyotishkumar, P., Eds.; WileyVCH Verlag GmbH \& Co. KGaA, 2015; pp 1-5. DOI: 10.1002/9783527645602.ch01.

(27) Gassner, F.; Owen, A. J. Physical properties of poly( $\beta$-hydroxybutyrate)-poly( $\varepsilon$ caprolactone) blends. Polymer (Guildf). 1994, 35 (10), 2233-2236. DOI: 10.1016/0032-3861(94)90258-5.

(28) Blümm, E.; Owen, A. J. Miscibility, crystallization and melting of poly (3hydroxybutyrate )/poly ( L-lactide ) blends. Polymer (Guildf). 1995, 36 (21), $4077-$ 4081. DOI: 10.1016/0032-3861(95)90987-D.

(29) Lovera, D.; Márquez, L.; Balsamo, V.; Taddei, A.; Castelli, C.; Müller, A. J. Crystallization, morphology, and enzymatic degradation of polyhydroxybutyrate/ polycaprolactone (PHB/PCL) blends. Macromol. Chem. Phys. 2007, 208 (9), 924-937. DOI: $10.1002 /$ macp.200700011.

(30) Garcia-Garcia, D.; Rayón, E.; Carbonell-Verdu, A.; Lopez-Martinez, J.; Balart, R. Improvement of the compatibility between poly(3-hydroxybutyrate) and $\operatorname{poly}(\varepsilon-$ caprolactone) by reactive extrusion with dicumyl peroxide. Eur. Polym. J. 2017, 86, 41-57. DOI: 10.1016/j.eurpolymj.2016.11.018.

(31) Koyama, N.; Doi, Y. Miscibility, Thermal Properties, and Enzymatic Degradability of Binary Blends of Poly[(R)-3-hydroxybutyric acid] with Poly(-caprolactone-co-lactide). Macromolecules 1996, 29 (30 mL), 5843-5851. DOI: 10.1021/ma9601191.

(32) Qiu, Z.; Ikehara, T.; Nishi, T. Poly(hydroxybutyrate)/poly(butylene succinate) blends: miscibility and nonisothermal crystallization. Polymer (Guildf). 2003, 44 (8), 25032508. DOI: 10.1016/S0032-3861(03)00150-2.

(33) Ma, P.; Hristova-Bogaerds, D. G.; Zhang, Y.; Lemstra, P. J. Enhancement in crystallization kinetics of the bacterially synthesized poly( $\beta$-hydroxybutyrate) by poly(butylene succinate). Polym. Bull. 2014, 71 (4), 907-923. DOI: 10.1007/s00289014-1101-x.

(34) Kozlowska, A.; Gromadzki, D.; El Fray, M.; Štěpánek, P. Morphology evaluation of biodegradable copolyesters based on dimerized fatty acid studied by DSC, SAXS and WAXS. Fibres Text East Eur 2008, 16, 85.

(35) Tallawi, M.; Zebrowski, D. C.; Rai, R.; Roether, J. A.; Schubert, D. W.; El Fray, M.; Engel, F. B.; Aifantis, K. E.; Boccaccini, A. R. Poly(Glycerol Sebacate)/Poly(Butylene 
Succinate-Butylene Dilinoleate) Fibrous Scaffolds for Cardiac Tissue Engineering. Tissue Eng. Part C Methods 2015, 21 (6), 585-596. DOI: 10.1089/ten.tec.2014.0445.

(36) Jäger, A.; Gromadzki, D.; Jäger, E.; Giacomelli, F. C.; Kozlowska, A.; Kobera, L.; Brus, J.; Ŕ́hová, B.; Fray, M. El; Ulbrich, K.; et al. Novel "soft" biodegradable nanoparticles prepared from aliphatic based monomers as a potential drug delivery system. Soft Matter 2012, 8 (16), 4343. DOI: 10.1039/C2SM07247E.

(37) Sonseca, A.; El Fray, M. Enzymatic synthesis of an electrospinnable poly(butylene succinate-co-dilinoleic succinate) thermoplastic elastomer. RSC Adv. 2017, 7 (34), 21258-21267. DOI: 10.1039/C7RA02509B.

(38) Correlo, V. M.; Boesel, L. F.; Pinho, E.; Costa-Pinto, A. R.; Alves Da Silva, M. L.; Bhattacharya, M.; Mano, J. F.; Neves, N. M.; Reis, R. L. Melt-based compressionmolded scaffolds from chitosan-polyester blends and composites: Morphology and mechanical properties. J. Biomed. Mater. Res. - Part A 2009, 91 (2), 489-504. DOI: 10.1002/jbm.a.32221.

(39) Groot, R. D.; Warren, P. B. Dissipative Particle Dynamics: Bridging the Gap between Atomistic and Mesoscopic Simulation. J. Chem. Phys. 1997, 107 (11), 4423. DOI: $10.1063 / 1.474784$

(40) Gooneie, A.; Schuschnigg, S.; Holzer, C. A Review of Multiscale Computational Methods in Polymeric Materials. Polymers (Basel). 2017, 9 (1), 16. DOI: 10.3390/polym 9010016 .

(41) Gooneie, A.; Nazockdast, H.; Shahsavan, F. Effect of selective localization of carbon nanotubes in PA6 dispersed phase of PP/PA6 blends on the morphology evolution with time, part 2: Relaxation of deformed droplets after cessation of flow. Polym. Eng. Sci. 2016, 56, 51-60. DOI: 10.1002/pen.24191.

(42) Sun, W.; Qiao, X.; Cao, Q.; Liu, J. Miscibility, Crystallization, and Rheological Behavior of Solution Casting Poly(3-hydroxybutyrate)/poly(ethylene succinate) Blends Probed by Differential Scanning Calorimetry, Rheology, and Optical Microscope Techniques. Chinese J. Chem. Phys. 2010, 23 (1), 107-112. DOI: 10.1088/16740068/23/01/107-112.

(43) Kitao, K. A study of brittle-ductile transition in polyethylene. Polym. Eng. Sci. 1997, 37 (5), 777-788. DOI: 10.1002/pen.11721.

(44) Gooneie, A.; Schuschnigg, S.; Holzer, C. Coupled Orientation and Stretching of Chains in Mesoscale Models of Polydisperse Linear Polymers in Startup of Steady Shear Flow Simulations. Macromol. Theory Simulations 2016, 25 (2), 170-186. DOI: 10.1002/mats.201500060.

(45) Choi, H. J.; Park, S. H.; Yoon, J. S.; Lee, H. S.; Choi, S. J. Rheological Study on Biodegradable Poly(3-Hydroxybutyrate) and Its Copolymer. J. Macromol. Sci. Part A 1995, 32 (sup1), 843-852. DOI: 10.1080/10601329508018975.

(46) Rocha, M. C. G.; Moraes, L. R. da C. Low Density Polyethylene (LDPE) blends based on Poly(3-Hydroxi-Butyrate) (PHB) and Guar Gum (GG) biodegradable polymers. Polímeros 2015, 25 (1), 42-48. DOI: 10.1590/0104-1428.1495.

(47) Lorenzo, M. L. Di; Raimo, M.; Cascone, E.; Martuscelli, E. Poly(3-hydroxybutyrate)- 
1

2

3

4

5

6

7

8

9

10

11

12

13

14

15

16

17

18

19

20

21

22

23

24

25

26

27

28

29

30

31

32

33

34

35

36

37

38

39

40

41

42

43

44

45

46

47

48

49

50

51

52

53

54

55

56

57

58

59

60

based copolymers and blends: influence of a second component on crystallization and thermal behavior. J. Macromol. Sci. Part B 2001, 40 (5), 639-667. DOI: 10.1081/MB100107554. 


\section{For Table of Contents Use Only}

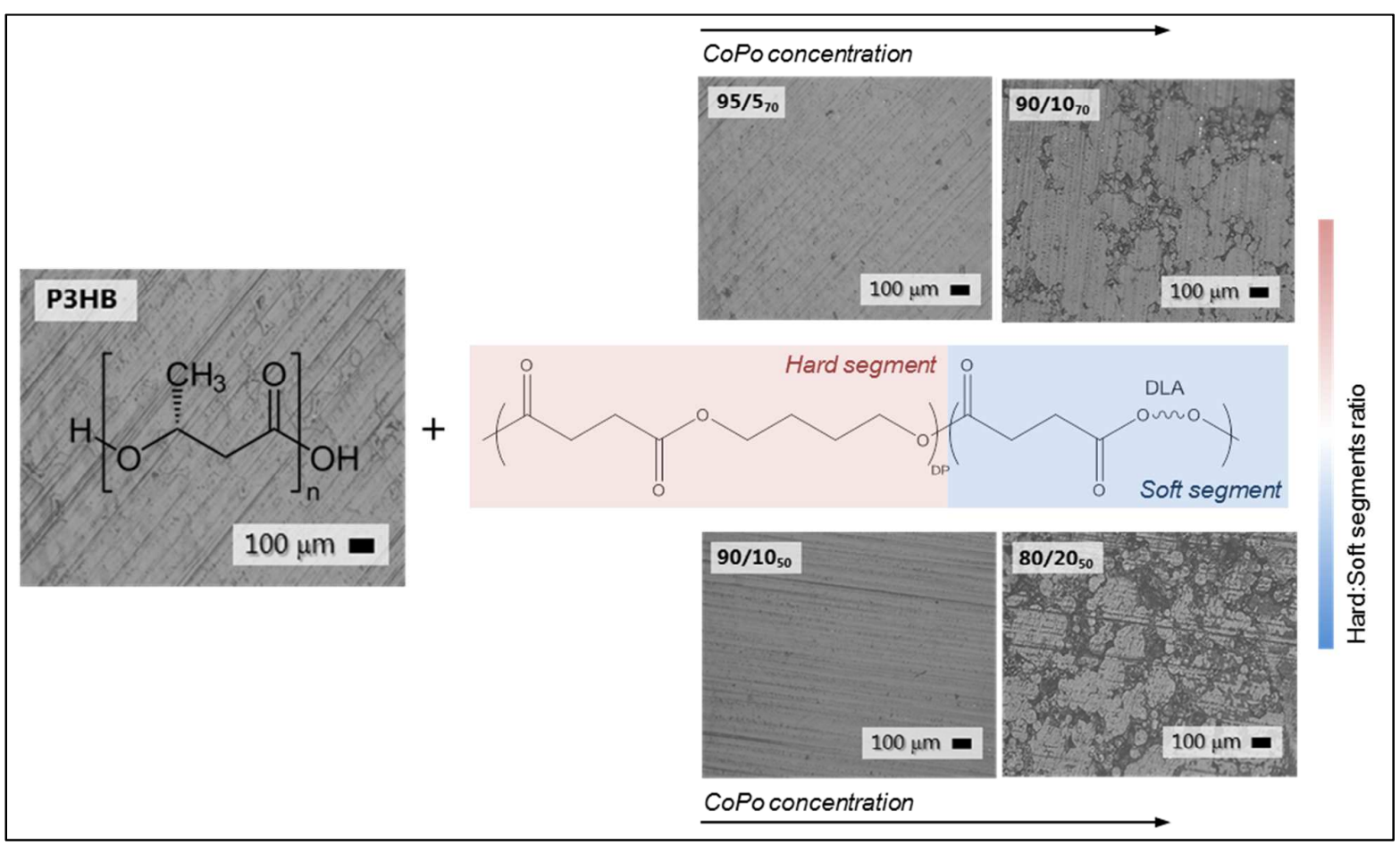

Synopsis: Evaluation of a segmented bio-copolymer as additive in P3HB melt-processing to improve polymer processability and prepare new green biomaterials. 